\title{
Efecto del manejo forestal sobre algunos servicios ecosistémicos en los bosques templados de México
}

\author{
Effects of forest management on some ecosystem \\ services in temperate forest ecosystems of Mexico
}

\author{
José Carlos Monárrez-González², Gustavo Pérez-Verdíni, Celia López-González', Marco Antonio Márquez-Linares y \\ María del Socorro González-Elizondol
}

Instituto Politécnico Nacional. CIIDIR Durango. Durango, Dgo., México. 2 Instituto Nacional de Investigaciones Forestales,
Agrícolas y Pecuarias. C.E. Valle del Guadiana. Durango, Dgo., México.

\section{RESUMEN}

Un elemento clave para favorecer un manejo forestal sustentable es conocer las compensaciones, sinergias y relaciones de los servicios ecosistémicos generados por los bosques. Este estudio tuvo como objetivo describir la relación entre el manejo forestal y algunos servicios ecosistémicos, en particular la conservación de la diversidad vegetal, producción de madera, regulación de los flujos del agua y el secuestro y almacenamiento de carbono en bosques templados de México. Se revisaron varias bases de datos bibliográficos para encontrar los estudios más relacionados con estos temas, compilándose 57 trabajos. El manejo forestal se materializa a través de prácticas que incluyen aclareos, cortas de regeneración, selección y otros tratamientos complementarios. De manera general, el manejo forestal impacta de forma positiva el abastecimiento de madera (materia prima) y el secuestro y almacén de carbono. Tiene un efecto variable en la conservación de la diversidad vegetal y negativo en el abastecimiento de flujos de agua, al menos al inicio de la intervención silvícola. El impacto y resiliencia del ecosistema depende de la escala espacial y temporal de la perturbación. La identificación, cuantificación y evaluación de las interacciones de los servicios ecosistémicos en los bosques templados de México, puede ayudar a los tomadores de decisiones a minimizar los impactos posibles del manejo forestal sobre los servicios ecosistémicos.

PALABRAS CLAVE: diversidad vegetal, flujos de agua, prácticas silvícolas, producción de madera, secuestro y almacén de carbono.

\section{ABSTRACT}

A key element to favor sustainable forest management is to know the trade-offs and synergy relationships of ecosystem services generated by forests. The purpose of this study was to describe the relationship between forest management and some ecosystem services, namely plant diversity, timber production, regulation of water flows, and carbon sequestration in temperate forests of Mexico. Several bibliographic databases were reviewed to find the publications related with those subjects, eventually compiling 57 studies. The forest management applied is materialized through silvicultural practices that include thinning, regeneration, and selection cuts. In general, forest management has a positive impact on the provision of wood (raw material) and carbon sequestration. It has a variable effect on the conservation of plant diversity and it is negatively correlated with the flow of water, at least at the beginning of the silvicultural intervention. The impact and resilience of the ecosystem depends on the spatial and temporal scale of the disturbance. The identification, quantification, and evaluation of ecosystem services interactions in temperate forests of Mexico could help decision makers to understand and minimize the potential impacts of forest management on ecosystem services.

KEYWORDS: plant diversity, water flows, silvicultural practices, wood production, carbon sequestration.

\section{INTRODUCCIÓN}

La definición de ecosistema, visto como "un sistema compuesto de procesos físicos, químicos y biológicos que operan como parte de una unidad espacio-temporal" inicia desde que Tansley (1935) diera a conocer el término y Lindeman (1942) propusiera estudiar las interacciones entre los organismos para comprender su dinámica temporal de largo plazo. A consecuencia de los movimientos ambientalistas de la década de 1970, se reconocen los bienes y servicios ofrecidos por los ecosistemas a las poblaciones humanas y es mediante las publicaciones de Daily (1997) y Costanza et al. (1997) que se conceptualiza el término de servicios ecosistémicos (SE). Estos se definen como "aquellos 
beneficios que la población obtiene de los ecosistemas" (Millennium Ecosystem Assessment [MEA], 2005).

Galicia y Zarco (2014) identifican para los bosques templados de México 13 servicios principales, clasificándolos en cuatro categorías: provisión (alimentos, agua, madera, recursos químicos, recursos genéticos, bioenergía y recursos forestales no maderables), regulación (regulación climática, flujo de agua, purificación de contaminantes del aire, [prevención de] erosión del suelo y deslizamientos de tierra, captura de carbono), servicios culturales (comunitarios, recreativos, educativos) y de apoyo al hábitat (producción primaria, formación de suelo).

Los ecosistemas forestales proveen de manera simultánea, dinámica y compleja una gran diversidad de SE (alimentos, madera, regulación climática, calidad del aire, agua, recreación, entre otros) (Bennett, Peterson y Gordon, 2009; Rodríguez et al., 2006). El comprender cómo se relacionan entre sí y cómo son afectados por el manejo forestal representa un gran reto para los técnicos forestales. La relación entre el manejo forestal y los SE puede ser de compensación, de sinergia, o de no afectación. Mientras la compensación ocurre cuando un SE se reduce como consecuencia de incrementar el uso de otro, la sinergia implica que ante un incremento en un bien o servicio no se afecta o se afecta positivamente la provisión de otros SE (Haines-Young y Potschin, 2015; Bennett et al., 2009; Lee y Lautenbach, 2016; Rodríguez et al., 2006).

Por otra parte, el manejo forestal comprende las decisiones y actividades encaminadas al aprovechamiento, conservación y fomento de los recursos forestales de manera ordenada; procurando satisfacer las necesidades de la sociedad actual y futura (Aguirre-Calderón, 2015). Del manejo forestal elegido y la condición del ecosistema dependerá la capacidad de los bosques para proporcionar ciertos SE, modificándose el tipo, magnitud y su combinación relativa; ya que diferentes sistemas de manejo y diversos tipos de ecosistemas conducen a distintos resultados (Sing, Ray y Watts, 2015). En los bosques templados, el manejo forestal para el aprovechamiento de recursos forestales maderables se realiza bajo los enfoques regular e irregular. El manejo regular se caracteriza por tener una cosecha periódica, determinada por un turno comercial (edad de cosecha del arbolado), donde el bosque se renueva mediante plantación o regeneración natural (Gadow, Sánchez y Aguirre-Calderón,
2004). Contrariamente, el manejo irregular se caracteriza por no tener un turno y realizar el aprovechamiento durante un ciclo de corta (periodo de recuperación del volumen maderable extraído). El manejo forestal involucra la ejecución de un programa de prácticas silvícolas: métodos de regeneración (corta de árboles padre, corta de selección, cortas sucesivas y cortas totales o matarrasa) y todas las actividades de cultivo o tratamientos intermedios (aclareos, reforestaciones, quemas prescritas, cortas de saneamiento, podas, actividades de preparación del sitio, limpia, siembra directa, entre otras), que se han de realizar durante el periodo de administración del bosque.

Generalmente, los dueños de bosque tienen un interés alto en los $\mathrm{SE}$ con beneficios económicos inmediatos. Como consecuencia, el manejo forestal tradicional tiene como objetivo principal aumentar la producción de madera y su rentabilidad económica, restando importancia a otros servicios (AguirreCalderón, 2015; Galicia y Zarco-Arista, 2014; Torres-Rojo, Moreno-Sánchez y Mendoza-Briseño, 2016).

En México, el ecosistema de bosque templado representa 17.4\% (34 millones de hectáreas) de la superficie continental del país (195 millones de hectáreas) y agrupa al bosque mesófilo de montaña y al bosque de coníferas y latifoliadas (Instituto Nacional de Estadística y Geografía [Inegi], 2015). Económicamente, en 2015 generó 91\% (6 millones de metros cúbicos de madera de pino, encino, oyamel y otras coníferas) del total de producción forestal maderable del país, con valor de ocho mil millones de pesos (Inegi, 2016). En términos de diversidad vegetal, los bosques templados contribuyen con alrededor de 10000 especies, prácticamente una tercera parte de la flora nacional (Rzedowski, 1991).

Actualmente se reconocen 49 especies de Pinus para México (Gernandt y Pérez-De la Rosa, 2014) y 161 especies de Quercus (Valencia, 2004), situando a México como el segundo centro de diversidad mundial de ambos géneros. Con relación a la regulación climática, el total de carbono por hectárea almacenado en bosques de coníferas (Pinus spp.) y bosques de hoja ancha (Quercus spp.) en México, se estima en 179 t/ha y 153 t/ha respectivamente (Masera, Ordóñez y Dirzo, 1997). Torres-Rojo y Guevara (2002) determinaron el potencial de captura de carbono en los bosques templados de México en alrededor de 13.2 miles de millones de toneladas de $\mathrm{CO}_{2}$ por año, lo que representa $54 \%$ 
del total nacional (24.5 miles de millones de toneladas de $\mathrm{CO}_{2}$ por año). La cosecha de agua es uno de los principales servicios ecosistémicos del bosque al propiciar la infiltración de agua a los mantos acuíferos. Para los bosques templados se estima en 1.2 billones de metros cúbicos de agua que representan 25\% del total nacional (4.8 billones de metros cúbicos de agua) (Torres y Guevara, 2002).

Los estudios de ecosistemas forestales templados y sus SE, particularmente en temas de productividad y calidad del bien y servicio ecosistémico generado, son muy escasos; las implicaciones de sus resultados son poco conocidas y por ende rara vez son considerados en la elaboración y ejecución de programas y planes de manejo forestales (Galicia y Zarco-Arista, 2014).

\section{Objetivos}

El objetivo del presente estudio fue hacer una revisión de los trabajos que se han desarrollado en bosques templados de México (BTM) y que han analizado el efecto que tiene el manejo forestal sobre muchos SE. En este caso, los SE que se incluyeron fueron la conservación de la diversidad vegetal, la provisión de madera (materia prima), la regulación de los flujos del agua y el almacén y secuestro de carbono. Estos fueron seleccionados debido a que son los mejor estudiados, a su grado de influencia en el bienestar de la sociedad y a su papel en el sostenimiento de los ecosistemas de BTM. En este trabajo se pretende responder las preguntas de investigación siguientes: ¿Cuál es el efecto o impacto del manejo forestal sobre los SE del bosque templado? y ¿Cómo es la relación de los SE, en un contexto de manejo forestal en los bosques templados? Se espera que esta investigación ayude a los manejadores forestales a entender las relaciones de compensación (trade-offs), entre manejo y SE; ya que por carecer de información, algunas acciones de manejo pueden tener como consecuencia resultados no deseados (Rodríguez et al., 2006).

\section{MATERIALES Y MÉTODOS}

Se revisó la literatura relacionada con el manejo forestal (MF) y sus efectos en los cuatro servicios ecosistémicos mencionados anteriormente. La revisión se limitó a los ecosistemas de BTM, dada su importancia forestal maderable. La búsqueda de información científica fue hecha usando las bases de datos de Thomson Reuters (Web of Science), Elsevier (Scopus, Science Direct), Springer (SpringerLink), Wiley (Wiley Online Library) y sitios Web (SciELO, Redalyc, Dialnet, Google Scholar, JURN), la recopilación abarca de enero de 1980 a febrero de 2017. Los criterios de selección fueron: (a) ser un estudio del ecosistema forestal templado de México y (b) que proporcione información útil sobre el efecto o impacto del manejo forestal sobre los SE a través de prácticas silvícolas. En estos trabajos se identificó la principal relación de la práctica silvícola sobre cada SE (positiva, negativa o nula). La revisión se organizó en tres partes: la primera da un contexto general de las investigaciones realizadas; la segunda describe y discute los efectos de las prácticas de manejo forestal por SE, y la última aporta conclusiones sobre esta revisión.

\section{RESULTADOS Y DISCUSIÓN}

De la revisión realizada, se recopilaron 57 publicaciones. Por servicio ecosistémico, los manuscritos se distribuyeron en provisión de madera ( $42 \%$ del total), conservación de la diversidad vegetal (35\%), almacenamiento y secuestro de carbono $(18 \%)$ y regulación de flujos de agua (5\%). Las prácticas silvícolas estudiadas incluyeron corta de árboles padre (AP), aclareo (ACL), corta de selección (CS), corta de matarrasa o corta total (CT), quema prescrita (QP), barbecho $(\mathrm{B})$, acomodo de desperdicios (AD), siembra directa (S), reforestación con planta (REF) y limpia (L). Las prácticas silvícolas mejor estudiadas $(90 \%$ de las investigaciones) fueron AP, CS, ACL y QP (Tabla 1). Los trabajos publicados en revistas y medios de difusión, destacaron en cantidad a partir del año 2003 (Fig. 1).

Derivado de este análisis, se observó que de manera general existe una dominancia de relaciones de sinergia entre el manejo forestal y los SE de provisión (producción de madera). Asimismo, existe una relación sinérgica con el secuestro y almacenamiento de carbón. Los resultados son variables en el caso de la diversidad dado que 12 estudios señalan una relación de compensación y otros ocho sugieren una relación de sinergia. Dado que se encontraron pocos estudios acerca de flujos de agua, es difícil obtener conclusiones. Aparentemente, la relación en este caso es de compensación, al menos en el corto plazo. 
TABLA 1. Investigación en México relacionada con los efectos del manejo forestal, sobre los cuatro tipos de bienes y servicios ecosistémicos en bosques templados de México.

\begin{tabular}{|c|c|c|c|c|c|c|c|c|}
\hline Referencia & $\begin{array}{l}\text { Ubicación } \\
\text { geográfica }\end{array}$ & $\begin{array}{l}\text { escala } \\
\text { espacial }\end{array}$ & $\begin{array}{l}\text { Tipo de } \\
\text { bosque }\end{array}$ & $\begin{array}{l}\text { Tratamiento } \\
\text { silvícolal }\end{array}$ & $\begin{array}{c}\text { Colecta } \\
\text { de } \\
\text { datos } \\
\text { (años) }\end{array}$ & $\begin{array}{c}\text { Servicio } \\
\text { ecosistémi } \\
\text { co }\end{array}$ & $\begin{array}{l}\text { Compo- } \\
\text { nente }\end{array}$ & $\begin{array}{c}\text { Efec- } \\
\text { to }\end{array}$ \\
\hline Razo-Zárate et al. (2013) & Hidalgo & Local & $\begin{array}{c}\text { oyamel- } \\
\text { encino- } \\
\text { pseudotsuga }\end{array}$ & $\mathrm{N}^{3}$ & 14 & Carbono & Almacén & + \\
\hline $\begin{array}{l}\text { Buendía-Rodríguez et al. } \\
\text { (2015) }\end{array}$ & $\begin{array}{l}\text { Edo. de } \\
\text { México }\end{array}$ & Local & $\begin{array}{l}\text { pino-oyamel- } \\
\text { encino } \\
\text { pino }\end{array}$ & CS & 53 & Carbono & Almacén & + \\
\hline Soriano-Luna et al. (2014) & Hidalgo & Local & pino & AP-CL-ACL & $1-22$ & Carbono & Almacén & + \\
\hline $\begin{array}{l}\text { Acosta-Mireles et al. } \\
(2009)\end{array}$ & Tlaxcala & Local & $\begin{array}{l}\text { oyamel-pino, } \\
\text { pino-oyamel, } \\
\text { pino }\end{array}$ & $A P, C S$ & $\mathrm{~N}^{3}$ & Carbono & Almacén & + \\
\hline $\begin{array}{l}\text { Pacheco-Aquino et al. } \\
\text { (2014) }\end{array}$ & Oaxaca & Local & pino-encino & $\begin{array}{c}\text { CS-AP-ACL- } \\
\text { CT }\end{array}$ & 8 & Carbono & captura & + \\
\hline Figueroa (2010) & $\begin{array}{l}\text { Edo. de } \\
\text { México }\end{array}$ & Local & pino & AP-CT & 3 a76 & Carbono & Captura & + \\
\hline Solís et al. (2014) & Durango & Local & pino-encino & AP-ACL-CS & $\mathrm{N}^{3}$ & Carbono & Suelo & + \\
\hline $\begin{array}{l}\text { Pérez-Ramírez et al. } \\
\text { (2013) }\end{array}$ & Michoacán & Regional & $\begin{array}{c}\text { oyamel } \\
\text { pino-encino }\end{array}$ & AP-CS & 16 y 25 & Carbono & Suelo & - \\
\hline Saynes et al. (2012) & Oaxaca & Regional & pino-encino & CS & $1-20$ & Carbono & Suelo & - \\
\hline Luis-Mejía et al. (2007) & Michoacán & Local & pino-encino & REF & $5-20$ & Carbono & Suelo & + \\
\hline Aparicio (2009) & Oaxaca & Local & pino-encino & AP-CS & 12 & Diversidad & Bromelías & $=$ \\
\hline Leyva-López et al. (2010) & Oaxaca & Local & pino-encino & AP & 15 & Diversidad & Arbórea & + \\
\hline $\begin{array}{l}\text { Alanís-Rodríguez et al. } \\
\text { (2008) }\end{array}$ & Nuevo León & Local & pino-encino & REF-AD & 10 & Diversidad & Arbórea & + \\
\hline $\begin{array}{l}\text { Alanís-Rodríguez et al. } \\
\text { (2010) }\end{array}$ & Nuevo León & Local & encino-pino & REF-AD & 10 & Diversidad & Arbórea & + \\
\hline $\begin{array}{l}\text { Castellanos-Bol et al. } \\
(2008)\end{array}$ & Oaxaca & Local & pino & AP-CS & $10-15$ & Diversidad & Arbórea & $=$ \\
\hline Graciano (2001) & Durango & Regional & pino-encino & AP-ACL-CS & $10-15$ & Diversidad & Arbórea & - \\
\hline Valdés et al. (2003) & Oaxaca & Local & pino-encino & AP-QP & 5 & Diversidad & $\begin{array}{l}\text { Ectomi- } \\
\text { corrizas }\end{array}$ & - \\
\hline $\begin{array}{l}\text { Villanueva-Jiménez et al. } \\
\text { (2006) }\end{array}$ & Oaxaca & Local & pino-encino & CS & $10-12$ & Diversidad & Hongos & - \\
\hline Valdés et al. (2009) & Oaxaca & Local & pino-encino & AP-QP & 6 & Diversidad & $\begin{array}{l}\text { Ectomi- } \\
\text { corrizas }\end{array}$ & - \\
\hline $\begin{array}{l}\text { Alfonso-Corrado et al. } \\
\text { (2014) }\end{array}$ & Oaxaca & Local & pino & AP-REF & 1,5 y 18 & Diversidad & Genética & $=$ \\
\hline $\begin{array}{l}\text { Hernández-Salas et al. } \\
\text { (2013) }\end{array}$ & Chihuahua & Local & pino-encino & CS & 10 & Diversidad & Arbórea & - \\
\hline Luna-Bautista (2014) & Oaxaca & Local & pino-encino & AP-ACL-CS & $12-15$ & Diversidad & $\begin{array}{c}\text { Arbórea, } \\
\text { arbustiva y } \\
\text { herbácea }\end{array}$ & - \\
\hline $\begin{array}{l}\text { Luna-Bautista et al. } \\
\text { (2015) }\end{array}$ & Oaxaca & Local & pino-encino & AP-ACL-CS & $12-15$ & Diversidad & $\begin{array}{c}\text { Arbórea, } \\
\text { arbustivo y } \\
\text { herbáceo }\end{array}$ & - \\
\hline Solís et al.(2006) & Durango & Local & pino-encino & CS-ACL & $>5$ & Diversidad & Arbórea & $=$ \\
\hline Corral et al. (2005) & Tamaulipas & Local & $\begin{array}{l}\text { liquidámbar- } \\
\text { encino carya- } \\
\text { encino }\end{array}$ & CS & 15 & Diversidad & Arbórea & - \\
\hline $\begin{array}{l}\text { Espinoza-Martínez et al. } \\
(2008)\end{array}$ & $\begin{array}{l}\text { Ciudad de } \\
\text { México }\end{array}$ & Local & pino & QP & $2-3$ & Diversidad & $\begin{array}{l}\text { Sineco- } \\
\text { logía }\end{array}$ & + \\
\hline
\end{tabular}




\begin{tabular}{|c|c|c|c|c|c|c|c|c|}
\hline Referencia & $\begin{array}{l}\text { Ubicación } \\
\text { geográfica }\end{array}$ & $\begin{array}{l}\text { escala } \\
\text { espacial }\end{array}$ & $\begin{array}{l}\text { Tipo de } \\
\text { bosque }\end{array}$ & $\begin{array}{l}\text { Tratamiento } \\
\text { silvícolal }\end{array}$ & $\begin{array}{c}\text { Colecta } \\
\text { de } \\
\text { datos } \\
\text { (años) }\end{array}$ & $\begin{array}{c}\text { Servicio } \\
\text { ecosistémi } \\
\text { co }\end{array}$ & $\begin{array}{l}\text { Compo- } \\
\text { nente }\end{array}$ & $\begin{array}{c}\text { Efec- } \\
\text { to }\end{array}$ \\
\hline Ramírez (2006) & Oaxaca & Regional & pino-encino & AP-CS & $10-12$ & Diversidad & Arbórea & $=$ \\
\hline Hernández-López (2007) & Oaxaca & Regional & pino-encino & AP-ACL-CS & $14-17$ & Diversidad & Arbórea & - \\
\hline Wolf (2005) & Chiapas & Regional & pino-encino & AP-CS & $20-25$ & Diversidad & Epífitas & - \\
\hline Jiménez et al. (2014) & Oaxaca & Local & pino-encino & $\begin{array}{l}\text { AP-ACL-REF- } \\
\text { CS }\end{array}$ & 20 & Diversidad & Epífitas & - \\
\hline Pavón et al. (2012) & Hidalgo & Local & pino & CS & 3 & Madera & Raíces & $=$ \\
\hline Negreros y Snook (1984) & Oaxaca & Local & pino-encino & CS & 20 & Madera & $\begin{array}{l}\text { Producti- } \\
\text { vidad }\end{array}$ & + \\
\hline $\begin{array}{l}\text { Armendáriz y Tena } \\
\text { (2004) }\end{array}$ & Chihuahua & Local & pino & $A C L$ & 3-14-17 & Madera & $\begin{array}{l}\text { Producti- } \\
\text { vidad }\end{array}$ & + \\
\hline Vázquez (2015) & Nuevo León & Local & pino & $A C L$ & $\begin{array}{l}\text { Monte } \\
\text { bravo }\end{array}$ & Madera & $\begin{array}{l}\text { Producti- } \\
\text { vidad }\end{array}$ & + \\
\hline Sánchez (2016) & Nuevo León & Local & pino & $A C L$ & $\begin{array}{l}\text { Monte } \\
\text { bravo }\end{array}$ & Madera & $\begin{array}{l}\text { Producti- } \\
\text { vidad }\end{array}$ & + \\
\hline $\begin{array}{l}\text { Castelán-Lorenzo y } \\
\text { Arteaga (2009) }\end{array}$ & Hidalgo & Local & pino & AP & $5-10$ & Madera & $\begin{array}{l}\text { Regene- } \\
\text { ración }\end{array}$ & + \\
\hline Valdés et al. (2006) & Oaxaca & Local & pino-encino & AP-QP & 14 & Madera & Raíces & $=$ \\
\hline Pérez et al. (2007) & Tlaxcala & Regional & $\begin{array}{c}\text { oyamel-pino } \\
\text { pino-oyamel } \\
\text { pino }\end{array}$ & AP-MT & 6,7 y 14 & Madera & $\begin{array}{l}\text { Regene- } \\
\text { ración }\end{array}$ & + \\
\hline $\begin{array}{l}\text { Goche-Télles et al. } \\
\text { (2003) }\end{array}$ & Puebla & Regional & pino-encino & $A C L$ & 5 & Madera & $\begin{array}{l}\text { Producti- } \\
\text { vidad }\end{array}$ & + \\
\hline Valdés et al. ( 2004) & Oaxaca & Local & pino-encino & AP-ACL-QP & $3-5$ & Madera & $\begin{array}{l}\text { Fitopató- } \\
\text { geno }\end{array}$ & - \\
\hline Rodríguez et al. (2010) & Oaxaca & Local & pino & $A C L$ & $9-15$ & Madera & $\begin{array}{l}\text { Producti- } \\
\text { vidad }\end{array}$ & + \\
\hline Núñez-López (2015) & Chihuahua & Regional & pino-encino & $A P-A C L$ & $\begin{array}{c}10,20 y \\
30\end{array}$ & Madera & $\begin{array}{l}\text { Producti- } \\
\text { vidad }\end{array}$ & + \\
\hline Flores et al. (2010) & Jalisco & Local & pino-encino & QP & $1-3$ & Madera & Quemas & + \\
\hline $\begin{array}{l}\text { Vera-Vilchis y Rodríguez } \\
\text { (2007) }\end{array}$ & $\begin{array}{l}\text { Edo. de } \\
\text { México }\end{array}$ & Local & pino & QP & 2 & Madera & Quemas & + \\
\hline $\begin{array}{l}\text { Hernández-Díaz et al. } \\
\text { (2008) }\end{array}$ & Durango & Regional & pino-encino & AP-ACL-CS & $\begin{array}{c}\text { Anualid } \\
\text { ades } \\
1995- \\
1996\end{array}$ & Madera & $\begin{array}{l}\text { Producti- } \\
\text { vidad }\end{array}$ & $=$ \\
\hline Chacón (1983) & Chihuahua & Local & pino-encino & AP & $2-3$ & Madera & $\begin{array}{l}\text { Regene- } \\
\text { ración }\end{array}$ & + \\
\hline Chacón et al. (1998) & Chihuahua & Local & pino-encino & $A P$ & $2-3$ & Madera & $\begin{array}{l}\text { Regene- } \\
\text { ración }\end{array}$ & + \\
\hline Bello et al. (2014) & Michoacán & Local & pino-encino & QP-B-L-S & $\begin{array}{c}2 \text { all } \\
\text { meses }\end{array}$ & Madera & $\begin{array}{l}\text { Regene- } \\
\text { ración }\end{array}$ & + \\
\hline $\begin{array}{l}\text { Ramírez-Santiago et al. } \\
\text { (2015) }\end{array}$ & Oaxaca & Local & pino-encino & AP-QP & 2 & Madera & $\begin{array}{l}\text { Regene- } \\
\text { ración e }\end{array}$ & + \\
\hline Valencia (1992) & Jalisco & Regional & pino-encino & AP & 8 & Madera & $\begin{array}{l}\text { Regene- } \\
\text { ración }\end{array}$ & + \\
\hline Estrada et al. (1995) & Chihuahua & Regional & pino-encino & $A C L$ & 29 & Madera & $\begin{array}{l}\text { Producti- } \\
\text { vidad }\end{array}$ & + \\
\hline $\begin{array}{l}\text { Acosta-Hernández et al. } \\
\text { (2011) }\end{array}$ & Veracruz & Regional & jJunglans & CS & 3 & Madera & $\begin{array}{l}\text { Morfo- } \\
\text { lógica }\end{array}$ & - \\
\hline $\begin{array}{l}\text { Aguirre-Calderón y } \\
\text { Jiménez (2011) }\end{array}$ & Nuevo León & Regional & pino-encino & $\mathrm{N}$ & 50 & Madera & $\begin{array}{l}\text { Producti- } \\
\text { vidad }\end{array}$ & + \\
\hline $\begin{array}{l}\text { Návar y González } \\
\text { Elizondo (2009) }\end{array}$ & Durango & Regional & pino-encino & CS & $\begin{array}{l}15,19 \\
27,37\end{array}$ & Madera & $\begin{array}{l}\text { Producti- } \\
\text { vidad }\end{array}$ & + \\
\hline $\begin{array}{l}\text { Alanís-Morales et al. } \\
\text { (2000) }\end{array}$ & Chihuahua & Local & pino-encino & QP & 4 & Agua & $\begin{array}{l}\text { Escurri- } \\
\text { miento }\end{array}$ & - \\
\hline
\end{tabular}




\begin{tabular}{|c|c|c|c|c|c|c|c|c|}
\hline Referencia & $\begin{array}{l}\text { Ubicación } \\
\text { geográfica }\end{array}$ & $\begin{array}{l}\text { escala } \\
\text { espacial }\end{array}$ & $\begin{array}{l}\text { Tipo de } \\
\text { bosque }\end{array}$ & $\begin{array}{l}\text { Tratamiento } \\
\text { silvícolal }\end{array}$ & $\begin{array}{c}\text { Colecta } \\
\text { de } \\
\text { datos } \\
\text { (años) }\end{array}$ & $\begin{array}{c}\text { Servicio } \\
\text { ecosistémi } \\
\text { co }\end{array}$ & $\begin{array}{l}\text { Compo- } \\
\text { nente }\end{array}$ & $\begin{array}{c}\text { Efec- } \\
\text { to }\end{array}$ \\
\hline $\begin{array}{l}\text { Dueñez-Alanís et al. } \\
\text { (2006) }\end{array}$ & Durango & Local & pino-encino & AP-ACL & 2 & Agua & $\begin{array}{l}\text { Infiltración } \\
\text { y escurri- } \\
\text { miento }\end{array}$ & $=$ \\
\hline $\begin{array}{l}\text { Muñoz-Villers et al. } \\
\text { (2012) }\end{array}$ & Veracruz & Local & $\begin{array}{l}\text { encino- } \\
\text { clethra- } \\
\text { miconia- } \\
\text { paratheis }\end{array}$ & $\mathrm{N}$ & 2 & Agua & $\begin{array}{c}\text { Balance de } \\
\text { agua }\end{array}$ & $=$ \\
\hline
\end{tabular}

Nota: 'Tratamiento silvícola: Corta de árboles padre (AP), aclareo (ACL), corta de selección (CS), corta de matarrasa o corta total (CT), quema prescrita (QP), barbecho (B), acomodo de desperdicios (AD), siembra directa (S), reforestación con planta (REF), limpia (L); ${ }^{2}$ Tipo de efecto: sinergia (+), compensación (-) y nulo (=); ${ }^{3}$ nnformación: no determinada ( $N$ )

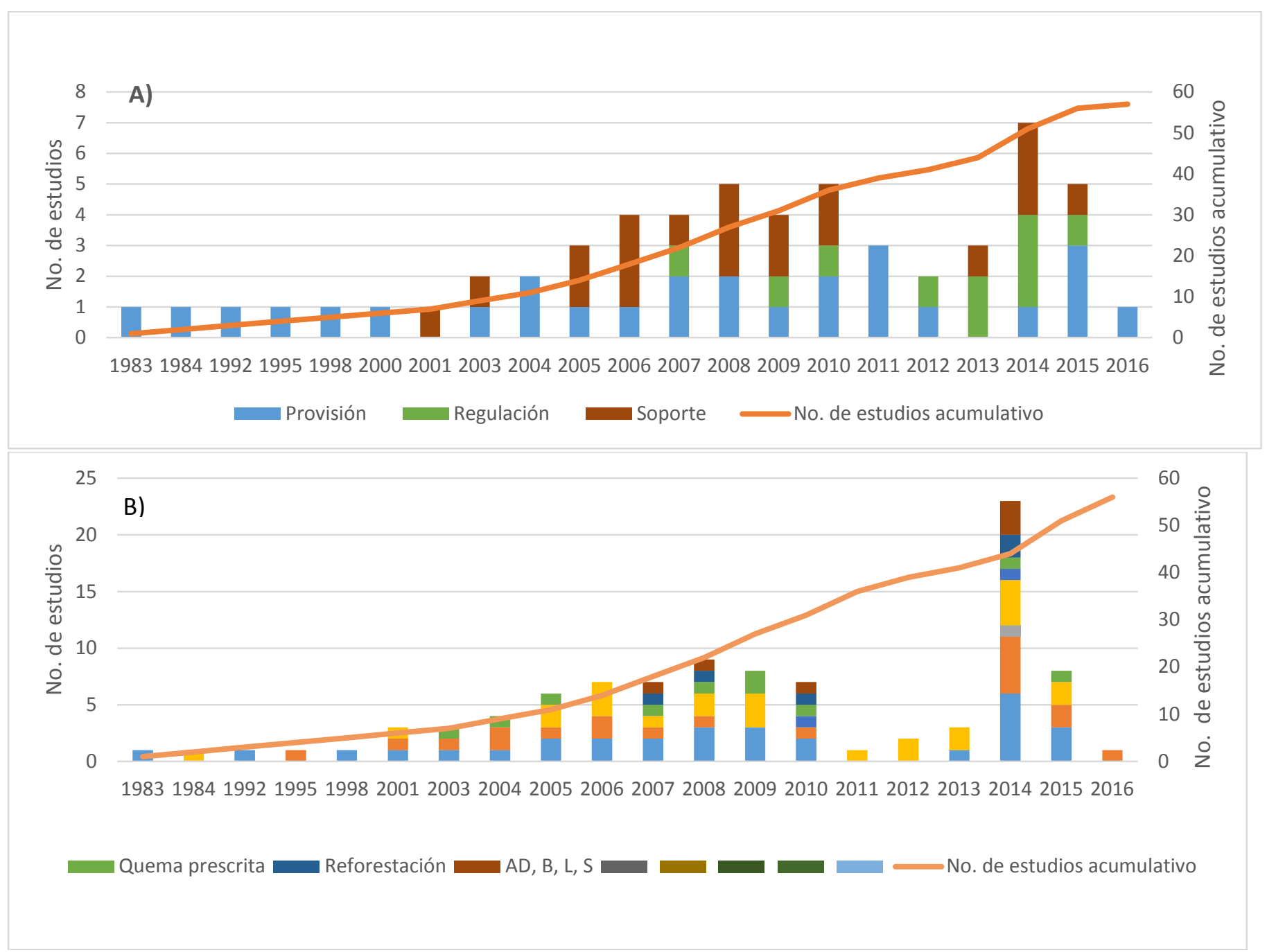

FIGURA 1. Frecuencia de estudios relacionados con los efectos del manejo forestal, sobre servicios ecosistémicos en bosques templados de México.

Fig. (A) Muestra el número de estudios por categoría de servicio ecosistémico y Fig. (B) por tratamiento silvícola. 
En un meta-estudio desarrollado por Lee y Lautenbach (2016), se encontró que la relación de sinergia fue dominante en los servicios de regulación, pero de compensación entre los servicios de provisión y regulación. Jackson et al. (2005) registraron reducciones sustanciales en el flujo de agua (regulación) con el incremento en la biomasa (provisión), lo cual indica una relación de compensación. Nótese que más biomasa significa mayor cantidad de carbón secuestrado, lo que también sugiere una relación de compensación entre contenido de carbón y flujo de agua. De la misma manera, Galicia y Zarco-Arista (2014) concluyeron que existen relaciones de compensación entre servicios de provisión (producción de madera) y de regulación (purificación de agua, retención del suelo y control de deslaves).

Las diferencias en el tipo de relación están asociadas a los distintos regímenes de manejo forestal, la escala (espacial y temporal) y al sistema socio-ecológico que se encuentre en el área (Rodríguez et al., 2006 y Bennett et al., 2009). Por ejemplo, los aclareos (por lo bajo, alto, etc.) pueden afectar la diversidad vegetal dependiendo de su intensidad y estructura meta del bosque. También, un mismo SE puede tener una relación de sinergia, cuando años atrás fue de compensación (Rodríguez et al., 2006). Sin embargo, la implicación clave en el conocer este tipo de relaciones es entender los procesos complejos que ocurren en la naturaleza y cómo interviene la sociedad. El reducir compensaciones no deseadas y/o fomentar las sinergias debe ser una meta común entre los manejadores forestales.

\section{Efectos del manejo forestal sobre la conservación de la diversidad vegetal}

La biodiversidad vegetal tiene múltiples roles en la provisión de SE; por ejemplo, como regulador fundamental de los procesos ecosistémicos, como servicio final en sí mismo y como un bien ecosistémico, sujeto a valoración económica o no (Mace, Norris y Fitter, 2012). La conservación de la diversidad vegetal es fundamental para la vitalidad de los ecosistemas forestales, siendo un servicio ecosistémico de apoyo o soporte.

Los estudios muestran que el efecto del manejo forestal en la diversidad vegetal es muy variable. Algunos autores encontraron una relación de sinergia entre el manejo forestal y la diversidad arbórea (Alanís-Rodríguez et al., 2010; Leyva-López, Velázquez-Martínez y Ángeles-Pérez, 2010), pero otros encontraron una relación de compensación (Graciano, 2001 y Hernández-Salas et al., 2013). Aunque es difícil explicar los detalles específicos de estos estudios, las diferencias, como se mencionó anteriormente, pueden deberse al tipo de manejo forestal, el tamaño del área y a la participación de los productores o manejadores forestales, entre otros.

Los bosques de México tienen una gran diversidad de especies en sus diferentes estratos, ejemplo de ello es la diversidad micológica (Garibay-Orijel et al., 2009). Por ejemplo, en un bosque de pino-encino, la diversidad del género Amanita en áreas sin manejo fue mayor que en áreas con aprovechamiento maderable (10 años de aplicada la corta), ya que el área con manejo presenta menor densidad de árboles, baja humedad relativa, mayor compactación del suelo y menor capa de humus (Villanueva-Jiménez, Villegas-Ríos, Cifuentes-Blanco y LeónAvendaño, 2006). En áreas con tratamiento de AP y AP + quema prescrita, la simbiosis del hongo fue mayor en el tratamiento sin quema prescrita (Valdés, Córdova, Gómez y Fierros, 2003; Valdés, Pereda, Ramírez, Valenzuela y Pineda, 2009).

$\mathrm{El}$ aprovechamiento forestal puede afectar la diversidad de epífitas en los bosques. Wolf (2005) identificó un efecto negativo de la explotación forestal sobre la diversidad de 74 especies de epífitas en bosques de Chiapas, que mostraron mayor resiliencia en áreas con menor perturbación. De la misma manera, en Oaxaca se encontró que la mayor diversidad de epífitas estaba en áreas sin y con manejo de primer aclareo, de cosecha y regeneración de rodales; y la menor diversidad en tratamiento de árboles padre con y sin reforestación de pino (Jiménez, Damona, Ochoa-Gaona y Clark, 2014). También en Oaxaca, Aparicio (2009) evaluó la diversidad de bromelias epífitas (12 especies), encontrándose que el manejo forestal después de un periodo de recuperación largo (hasta 20 años) no afectó su diversidad. De lo anterior, se concluye que la pérdida de diversidad y abundancia de epífitas se debe a la corta de árboles, pero puede reestablecerse una vez que la masa arbórea se recupera.

Diversos estudios han registrado cambios en la diversidad arbórea como resultado del manejo forestal. En Chihuahua, en un área sin manejo y con manejo (corta de selección, aclareo ligero, árboles padre a 12 años - 15 años de su aplicación), la diversidad arbórea fue mayor en el bosque sin manejo. La mayor diversidad en especies herbáceas y arbustivas se encontró en los 
tratamientos silvícolas de árboles padre y aclareo ligero (LunaBautista, Hernández-De La Rosa, Velázquez-Martínez, GómezGuerrero y Acosta-Mireles, 2015). Aunque el tratamiento de corta de selección mantiene el número de especies arbóreas, el género Pinus aumenta en abundancia, dominancia, frecuencia e índice de valor de importancia, mientras que la abundancia del género Quercus decrece y Juniperus se mantiene estable (Hernández-Salas et al., 2013). Algunos autores mencionan que hay mayor diversidad de especies en rodales sin manejo que aquellos con manejo (Hernández, 2007; Ramírez, 2006; Valdés et al., 2003). Sin embargo, Leyva-López et al. (2010) no encontró diferencias de diversidad arbórea entre un área con y sin manejo forestal. Esto último pudo deberse a que las áreas evaluadas fueron medidas en un periodo de recuperación más largo, donde hubo incorporación de especies por la regeneración natural existente e influida por rodales circundantes (15 años después de la aplicación de corta).

En los bosques de la región sur de Durango, las cortas de selección han reducido la diversidad arbórea, ya que solo se cosechan los árboles dominantes de importancia maderable (Pinus cooperi y P. durangensis) (Graciano, 2001). Los aclareos promueven la abundancia de Pinus spp., mientras que las cortas selectivas mantienen una mayor diversidad de especies. Las cortas selectivas implican una disminución en la abundancia y número de especies, menor variabilidad de distribución y mayor homogeneidad en la estructura de los bosques de pino-encino (Corral-Rivas, AguirreCalderón, Jiménez-Pérez y Corral, 2005; Solís et al., 2006).

En bosques de Pinus patula, la mayor diversidad arbórea se presenta en la condición silvícola de fustal medio y fustal viejo, el mayor grado de mezcla en fustal viejo y la dominancia de pino aumenta conforme la condición se desarrolla (CastellanosBolaños et al., 2008). Al evaluar el efecto en su diversidad genética, se concluyó que $P$. patula no ha sido depauperado genéticamente por el manejo forestal presente y pasado y tiene características en su historia de vida que promueven la diversidad genética, como tasas altas de entrecruzamiento (Alfonso-Corrado, CamposContreras, Sánchez-García, Monsalvo Reyes y Clark-Tapia, 2014). Acosta-Hernández et al. (2011) concluyeron en un bosque mesófilo de montaña que las prácticas de aprovechamiento forestal basadas únicamente en los mejores individuos provocan la pérdida genética y la declinación del bosque debido a que el aprovechamiento afecta la composición y diversidad vegetal.
Los incendios forestales también provocan cambios en la diversidad arbórea. En bosques del estado de Nuevo León, al comparar un área natural con una área perturbada por incendio forestal, a 10 años de aplicada la reforestación, la diversidad arbórea tuvo una similitud media-alta y no se presentaron diferencias en términos de abundancia (Alanís-Rodríguez et al., 2008, 2010).

\section{Efectos del manejo forestal sobre la provisión de madera}

La aplicación inadecuada de los métodos de manejo puede originar graves problemas de degradación de las áreas naturales bajo aprovechamiento, cambios notables en la composición de especies y fuertes problemas de fragmentación que evidentemente influyen en la baja productividad de las áreas forestales y en la salud de los ecosistemas (Torres-Rojo, 2004). Sin embargo, cuando el manejo es adecuado, la masa forestal tiende a regenerarse mejor. Por ejemplo, en bosques de pino encino en Chihuahua, manejados con el Método de Desarrollo Silvícola, Nuñez et al. (2015) determinaron que a partir de la segunda medición, los promedios en área basal, biomasa y crecimientos producidos fueron mayores en el área con tratamientos silvícolas aplicados que las áreas sin manejo.

En áreas de bosque con especies dominantes de Abies religiosa-Pinus patula, A. religiosa-P. montezumae, P. teocote y $P$. rudis, Pérez-Segura, Guerra de la Cruz, Carrillo Anzures, Acosta Mireles y Buendía Rodríguez (2007) concluyeron que el método de árboles padre (10 años a 14 años de aplicada la corta) tuvo una respuesta limitada en el establecimiento de la regeneración de coníferas, en comparación a la corta de matarrasa (en área no mayor a $2500 \mathrm{~m}^{2}$, 6 años - años post tratamiento) que tuvo densidades de hasta 3000 plantas por hectárea. Resultados similares obtuvieron Ramírez-Santiago et al. (2015) en un bosque de pino-encino en Oaxaca. Al aplicar la corta de matarrasa con quema de residuos, después de dos años, los autores obtuvieron alrededor de $1450 \pm 640.31$ plántulas emergidas por hectárea, con un promedio de supervivencia de $800 \pm 489.89$ plántulas por hectárea.

En bosques de P. patula con corta de árboles padre, la regeneración se comportó de manera regular y uniforme (densidad de 4200 plantas por hectárea), considerándola 
establecida a los cuatro años del aprovechamiento (CastelánLorenzo y Arteaga-Martínez, 2009). Chacón (1983) y Chacón, Velázquez y Musálem (1998) para un bosque de P. arizonica, determinaroó que 20 árboles por hectárea es el ideal para el establecimiento de la regeneración $\left(345 \mathrm{~m}^{2} /\right.$ ha de cobertura). Por su parte, Valencia (1992) en un bosque de pino-encino en Jalisco, determinó que las variables: grosor de hojarasca, competencia de vegetación herbácea, número de piedras y número de árboles por hectárea dejados en pie, tenían mayor poder de explicación en el número de plantas de regeneración natural establecidas.

En un bosque de Pinus pseudostrobus, Bello, Segura, Tinoco, Lara y Salgado (2014) determinaron que las densidades de 88 y 140 árboles por hectárea presentan una mayor emergencia de plántulas (mayor a 34\%) y al combinar con barbecho y limpia se obtuvo una supervivencia de $70 \%$ y $90 \%$ en regeneración de cinco y ocho meses de edad. Estos resultados sugieren que los tratamientos intensivos como la corta de árboles padre, aseguran la regeneración del bosque y no ponen en riesgo su dinámica de crecimiento.

Los aclareos deben eliminar los árboles más defectuosos y dejar un reparto homogéneo de los árboles en la superficie, con el fin de aprovechar el máximo potencial de crecimiento del sitio (Estrada, Dominguez y Zepeda, 1995). En un bosque coetáneo (14 años - 17 años) de Pinus arizonica, Armendáriz y Tena (2004) determinaron que 1600 árboles por hectárea fue la densidad residual con mayor crecimiento de volumen, comparada con un rodal sin manejo que presentó una disminución en su crecimiento. Vázquez (2015) y Sánchez (2016) concluyeron que los mayores crecimientos se obtuvieron de aclareos con intensidad de remoción de $60 \%$ en rodales de $P$. rudis en Nuevo León, en la etapa de crecimiento de monte bravo y a tres años de aplicado el tratamiento. Resultados similares se encontraron por Rodríguez (2010) en rodales de Pinus patula, donde un aclareo de 40\% a 69\% generó un incremento de $75 \%$ en diámetro y $52 \%$ en altura. Estos resultados implican que bosques con un manejo adecuado de la densidad (aplicación de aclareos) generan una productividad maderable mayor que aquellas áreas sin manejo.

Las raíces son indicadores funcionales del ecosistema ya que constituyen gran parte de la biomasa viva del suelo y ejercen un control sobre los procesos de pedogénesis, la producción de materia orgánica y la dinámica de los nutrientes (Pavón, Moreno y Ramirez-Bautista, 2012). La biomasa de raíces no varía entre áreas con tratamiento de corta de selección (3.05 t/ha) y sin manejo (3.39 t/ha) (Pavón et al., 2012).

Los esquemas nuevos de manejo del fuego involucran un uso mayor de quemas prescritas, por lo que es necesario investigar los efectos de estas y de los incendios (Flores, Xelhuantzi y Chavéz, 2010). En bosques de Pinus hartwegii es factible el uso de quemas prescritas de baja intensidad para promover la diversidad y riqueza de especies en el sotobosque, pudiendo además aumentar el crecimiento de la altura del arbolado juvenil (Espinoza-Martínez, Rodríguez-Trejo y Zamudio-Sánchez, 2008; Vera-Vilchis y Rodríguez-Trejo, 2007). Al estudiar la población del hongo parásito Armillaria mellea, esta fue mayor en la parcela quemada que la parcela tratada sin fuego (Valdés et al., 2004).

\section{Efectos de manejo forestal sobre regulación de los flujos del agua}

El agua tiene tres roles en los ecosistemas forestales: como servicio de provisión (agua dulce), como servicio de regulación (calidad y temporalidad) y como servicio de soporte (ciclo hidrológico) (Balvanera y Cotler, 2009). El agua entra en el ecosistema terrestre principalmente a través de la precipitación y lo abandona por evapotranspiración, escorrentía e infiltración (Muñoz-Villers et al., 2012).

Dueñez-Alanís, Gutiérrez, Pérez y Návar (2006) estudiaron un área de pastizal y la aplicación de tres tratamientos silvícolas en un bosque con manejo silvopastoril en Durango. El primer año, en el tratamiento de segundo aclareo se encontró una mayor infiltración, menor flujo superficial de agua y mayor concentración de sedimentos. En contraste, en el tercer aclareo y corta de regeneración no se registraron tasas erosivas. En el segundo año, en general, la concentración de sedimentos disminuyó entre 13\% y 50\%, la escorrentía disminuyó, la infiltración incrementó en casi 150\% y la tasa erosiva se redujo hasta 53\%. Los valores de la tasa erosiva disminuyeron en mayor grado en la corta de regeneración y en el pastizal. No se observaron diferencias entre tratamientos, pero sí entre el área de pastizal y los bosques. El pastizal en los dos años de medición mostró las mayores tasas de escorrentía y erosión, así como la menor tasa de infiltración. Lo anterior muestra que las actividades de extracción forestal pueden tener un impacto temporal sobre 
las variables hidrológicas. De igual manera, al comparar el balance de agua de dos microcuencas, una de estructura forestal madura y otra con corta de regeneración de 20 años, Muñoz-Villers et al. (2012) señalaron que el bosque con aprovechamiento maderable fue capaz de producir un comportamiento hidrológico similar al área sin perturbación.

Las quemas prescritas afectan significativamente los flujos de agua. Alanís-Morales, Návar y Domínguez (2000) encontraron que el tratamiento de quema prescrita en bosques de Pinus arizonica triplicó el escurrimiento superficial del agua $(1.54 \%$ de la precipitación total), comparado con la condición previa sin tratamiento (escurrimiento $0.45 \%$ de la precipitación total). El efecto se debe a la remoción de la cubierta superficial del suelo que limita los escurrimientos. En ese trabajo, la relación entre escorrentía superficial y la profundidad de la hojarasca fue lineal y negativa, lo que indica que el volumen de escorrentía superficial disminuye con el aumento de hojarasca (Alanís-Morales et al., 2000).

Los párrafos anteriores implican que la intervención silvícola en el corto plazo (uno a cinco años), afecta los flujos del agua (mayor escurrimiento y menor infiltración), pero en un plazo largo (15 años - 20 años), una vez que se recupera la masa arbórea, el efecto de los tratamientos silvícolas sobre los flujos de agua no es perceptible.

\section{Efectos de manejo forestal sobre el secuestro y almacenamiento de carbón}

El uso de combustibles fósiles y el cambio en el uso del suelo se consideran como las dos fuentes principales de dióxido de carbono $\left(\mathrm{CO}_{2}\right)$ en la atmósfera. Los bosques son almacenes importantes para el mundo y son responsables de la mayor parte de los flujos de carbono entre la tierra y la atmosfera, a través de la fotosíntesis y la respiración (Mintzer, 1992; Tipper, 1998). A nivel mundial, el suelo almacena dos veces más carbono $(C)$ que la atmósfera y casi el doble de la cantidad almacenada por la vegetación (Pérez-Ramírez, Ramírez, Jaramillo-López y Bautista, 2013).

Pérez-Ramírez et al. (2013) encontraron que rodales conservados (sin manejo) de oyamel en Michoacán almacenan en promedio 153 t C/ha de carbono orgánico en el suelo (COS), valor que es $28 \mathrm{t} \mathrm{C} / \mathrm{ha}$ a $58 \mathrm{t} \mathrm{C} / \mathrm{ha}$ superior a rodales de oyamel perturbados y aprovechados, respectivamente. En bosques conservados de pino-encino, estos almacenan $103 \mathrm{t} \mathrm{C} /$ ha de COS que es de 64 t C/ha a 90 t C/ha más que los rodales de pinoencino aprovechados y perturbados. Un bosque de pino-encino en Oaxaca a 20 años de la extracción forestal maderable, observó una disminución en las concentraciones de carbono total, biomasa microbiana del suelo y respiración basal del suelo (Saynes, Etchevers, Galicia, Hidalgo y Campo, 2012). Para Durango, esté tipo de bosque presentó un contenido promedio de carbono orgánico de 58.10 t C/ha, con una concentración mayor de COS en la calidad de estación buena (63.12 t C/ha en los primeros $20 \mathrm{~cm}$ de suelo). No se identificaron diferencias de carbono ante la aplicación de tratamientos de corta de árboles padre, aclareos y corta de selección, pero si se observó que conforme aumenta el COS, mejora la calidad de estación (Solis et al., 2014).

Luis-Mejía et al., (2007), en reforestaciones con Pinus michoacana, hallaron que para profundidades de suelo de $0 \mathrm{~cm}$ a 5 $\mathrm{cm}$ y de $5 \mathrm{~cm}$ a $10 \mathrm{~cm}$ la fracción de carbono nuevo fue $61.8 \%$ y $17.6 \%$, respectivamente, y la tasa de acumulación de carbono en la profundidad $0 \mathrm{~cm}$ a $10 \mathrm{~cm}$ fue de $0.588 \mathrm{t} \mathrm{C} /$ ha por año. En los primeros $5 \mathrm{~cm}$ de suelo, se indica que las reforestaciones reducen la ganancia de carbono en los primeros cinco años, pero estas se duplican a los 20 años. Esto significa que la aplicación de cortas al bosque, en un plazo corto, disminuye la acumulación de carbono orgánico del suelo.

El almacenamiento de carbono en la parte aérea varía también entre tipos de bosques. En la región de Tlaxco, Tlaxcala los bosques de oyamel-pino tienen, por lo general, mayor cantidad de carbono (301.9 t C/ha) que los de pino (183.2 t C/ha) (Acosta-Mireles, Carrillo-Anzures y Díaz-Lavariega, 2009). En un bosque de oyamel en Hidalgo para un área en conservación se determinó una menor cantidad de carbono almacenado (62.6 t $\mathrm{C} / \mathrm{ha}$ en arboles vivos y muertos), mientras que el bosque aprovechado tuvo una mayor cantidad (166.6 t C/ha en arboles vivos y muertos) (Razo-Zárate, Gordillo-Martínez, RodríguezLaguna, Maycotte-Morales y Acevedo-Sandoval, 2013). Este último escenario es el mejor para el almacenamiento y secuestro de carbono debido a que las masas forestales se mantienen dinámicas por periodos de tiempo prolongados (Razo-Zárate et al., 2013). 
En rodales de bosque mixto en la región Sur de Nuevo León, se obtuvieron estimaciones de contenido de carbono para las diferentes asociaciones arbóreas: pino-encino (45.24 t C/ha), encino-pino (64.20 t C/ha), Pinus pseudostrobus (73.18 t C/ha) y de P. teocote ( $47.01 \mathrm{t} \mathrm{C} / \mathrm{ha}$ ) (Aguirre-Calderón y Jiménez-Pérez, 2011). De igual modo, Pacheco-Aquino, Durán-Medina y Ordóñez-Díaz (2014) para un bosque pino-encino manejado de Oaxaca estimaron el potencial de captura en $1.36 \mathrm{t} C /$ ha por año $( \pm 0.31 \mathrm{t} \mathrm{C} / \mathrm{ha})$ y el almacenamiento de carbono en $115.7 \mathrm{t} \mathrm{C} / \mathrm{ha}$, mostrando que a la par del aprovechamiento de madera, se captura y almacena carbono. Buendía-Rodríguez, Treviño-Garza, Aguirre-Carderón, Alanís y Acosta-Mireles (2015) refieren para un bosque mixto del Estado de México, un contenido de carbono para el área de aprovechamiento de 101.38 t C/ha y para un área sin perturbación de 59.92 t C/ha, se explica que el bosque bajo manejo generó mejores características estructurales y dinámicas, a diferencia de un bosque sin aprovechamiento que estabiliza su crecimiento. En un bosque de pino-encino con manejo forestal en Michoacán, se estimó el contenido de carbono de su biomasa en $71 \mathrm{t} \mathrm{C} /$ ha a $198 \mathrm{t} \mathrm{C} /$ ha (promedio $129.1 \mathrm{t} \mathrm{C} / \mathrm{ha}$ ); respecto a la captura potencial de carbono se estimó que el bosque fija $1.54 \mathrm{t}$ C/ha (Ordóñez-Díaz, Rivera Vázquez, Tapia Medina y Ahedo Hernández, 2015).

En un bosque de Pinus patula en Hidalgo, Soriano-Luna, Martínez-Trinidad, Plasencia-Escalante y Razo-Zarate (2014) estimaron que la mayor proporción de biomasa se distribuyó en el fuste $(68.2 \%)$, seguida de las ramas $(14.3 \%)$, corteza $(9.3 \%)$ y follaje $(8.2 \%)$. La biomasa tiene una relación directa con los contenidos de carbono, el cual tiene un valor aproximado de 0.5. Los valores de biomasa más bajos se observaron en los rodales jóvenes (1 año - 8 años). Por el contrario, en los rodales de mayor edad (20 años - 22 años de edad) los valores fueron $>100$ t C/ha de biomasa. En este tipo de ecosistema, Figueroa (2010) calculó que la cantidad de carbono almacenado se incrementó con la edad del rodal: el rodal de 25 años presentó una acumulación de carbono similar al contenido de un área que aún no había sido intervenida (86.40 t C/ha y 92.44 t C/ha, respectivamente); por tanto, es posible señalar que los bosques manejados pueden funcionar eficientemente como fijadores y sumideros de carbono; sin embargo, aún es necesario determinar los balances netos de flujo de carbono ante diferentes condiciones de manejo.

\section{CONCLUSIONES}

Este estudio trata de mostrar de forma descriptiva los efectos de la aplicación del manejo forestal en los bosques templados de México sobre cuatro SE: conservación de la diversidad vegetal, producción de madera (materia prima), regulación de los flujos del agua y secuestro y almacenamiento de carbono en México. La revisión de los documentos sugiere que la aplicación de manejo forestal a través de prácticas silvícolas (corta de árboles padre, aclareo, corta de selección, corta de matarrasa o corta total, quema prescrita, barbecho, acomodo de desperdicios, siembra directa, reforestación y limpia) impactan de forma positiva los SE de producción de madera (materia prima) y secuestro y almacenamiento de carbono. Sin embargo, la relación es diferente con los servicios de conservación de la diversidad vegetal y regulación de flujos de agua, los cuales al inicio de la intervención silvícola se afectan de forma negativa.

El impacto del manejo forestal sobre la conservación de la diversidad vegetal y regulación de flujos de agua, está relacionado con la intensidad del manejo, temporalidad y calidad productiva del bosque. Un manejo menos intensivo (menor remoción del estrato arbóreo), una temporalidad mayor de recuperación después de aplicado el tratamiento (al menos 20 años - 40 años) y una productividad alta, reducen el impacto en los SE.

Con el manejo forestal, en los primeros años de la intervención, el servicio de regulación de los flujos de agua se ve afectado de forma negativa; sin embargo, conforme el bosque se recupera de la perturbación, el servicio puede presentar un comportamiento hidrológico similar al de antes de la perturbación.

El servicio de secuestro y almacenamiento de carbono, por su relación directa con la biomasa, se afecta de forma similar que el servicio de producción de madera. En algunos estudios se demuestra que un bosque bajo manejo no intensivo, al tener una dinámica mayor de crecimiento, aumenta el potencial de captura y almacenamiento de carbono en comparación con bosques sin manejo.

La identificación, cuantificación y evaluación de las relaciones y formas de interacción de los SE en los bosques templados de México, permitirá generar un manejo forestal que realmente se encamine hacia la sustentabilidad. Los tomadores de decisiones podrán discernir sobre las posibles compensaciones y 
sinergias entre SE, particularmente cuando se privilegia aquellos SE con valor alto inmediato para los propietarios del recurso (producción de madera y almacenamiento de carbono), sobre otros como la diversidad y riqueza vegetal y la disponibilidad del agua.

Es necesario iniciar un proceso de monitoreo permanente en los distintos paisajes templados de México, el cual deberá involucrar de forma conjunta al menos los SE de conservación de la diversidad vegetal, el secuestro y almacenamiento de carbono, la producción de madera y la regulación de los flujos del agua. Dicho monitoreo deberá considerar las compensaciones, sinergias y no afectaciones entre SE a nivel espacial y temporal. Es de notar la relevancia que a dichos SE pueda cuantificárseles de forma económica a fin de poder fijar con mayor claridad para los dueños del recurso y sociedad en general, las repercusiones positivas y negativas de privilegiar ciertos SE sobre otros.

En cuanto a la conservación de la diversidad vegetal, se requiere contar con información fidedigna acerca del impacto del manejo sobre la composición de la cubierta herbácea, dada la relación directa entre esta y otros servicios como son la conservación del suelo y la infiltración y flujo de agua. Conocer la composición de especies es importante también para interpretar correctamente las cifras sobre riqueza o diversidad.

Se recomienda desarrollar una línea de investigación que aborde el efecto o impacto del manejo forestal, a través de sus prácticas silvícolas, sobre los SE. Se recomienda también un cambio de paradigma del cómo debe llevarse a cabo el manejo forestal, pudiendo ser un manejo multipropósito que considere la provisión de diversos bienes y servicios ecosistémicos y las incertidumbres a escala espacial (manejo del paisaje) y temporal de manera simultánea y que considere las percepciones de los propietarios de los terrenos forestales. Este cambio de paradigma necesariamente implica una visión del bosque como una red de relaciones entre organismos vivos que se da sobre un paisaje, y la comprensión de las especies maderables como uno de los múltiples componentes de un sistema dinámico el que cualquier modificación de una de sus partes redunda en la modificación de otras. Entender la magnitud y sentido de estos "trade offs" permite un mejor manejo forestal que permita tener beneficios económicos sin la pérdida del ecosistema y sus SE.

\section{RECONOCIMIENTOS}

Se agradecen los comentarios de los editores y revisores de esta revista. El Instituto Nacional de Investigaciones Forestales Agrícolas y Pecuarias (Inifap), el Consejo Nacional de Ciencia y Tecnología (Conacyt) y el Instituto Politécnico Nacional (IPN, a través de los proyectos SIP 2016-0386 y 2017-1358), aportaron recursos para el desarrollo de esta investigación.

\section{REFERENCIAS}

Acosta-Hernández, C. C., Luna-Rodríguez, M., Octavio-Aguilar, P., Morales-Romero, Z., Galindo-González, J., Noa-Carrazana, J. C., Iglesias-Andreu, L. G. (2011). Efecto del aprovechamiento forestal sobre la variación morfológica de Juglans pyriformis Liebm. Revista Chapingo Serie Ciencias Forestales y del Ambiente, 17(3), 379_ 388. doi: 105154/r.rchscfa2011.04.033

Acosta-Mireles, M., Carrillo-Anzures, F., \& Díaz-Lavariega, M. (2009). Determinación del carbono total en bosques mixtos de Pinus patula Schl. et Cham. Terra Latinoamericana, 27(2), 105-114.

Aguirre-Calderón, O. A. (2015). Manejo forestal en el Siglo XXI. Madera y Bosques, 21(Núm. esp.), 17-28. doi: 10.21829/myb.2015.210423

Aguirre-Calderón, O., \& Jiménez-Pérez, J. (2011). Evaluación del contenido de carbono en bosques del sur de Nuevo León. Revista Mexicana de Ciencias Forestales, 2(6), 73-84.

Alanís-Rodríguez, E., Jiménez-Pérez, J., Espinoza-Vizcarra, D., JuradoYbarra, E., Aguirre-Calderón, O., \& González-Tagle, M. (2008). Evaluación del estrato arbóreo en un área restaurada postincendio en el Parque Ecológico Chipinque, México. Revista Chapingo Serie Ciencias Forestales y del Ambiente, 14(2), 113-118.

Alanís-Rodríguez, E., Jiménez-Pérez, J., Pando-Moreno, M., AguirreCalderón, O. A., Treviño-Garza, E. J., \& García-Galindo, P. C. (2010). Efecto de la restauración ecológica post-incendio en la diversidad arbórea del Parque Ecológico Chipinque, México. Madera y Bosques, 16(4), 39-54. doi: 10.21829/myb.2010.1641159

Alanís-Morales, H., Návar, J., \& Domínguez, P. A. (2000). The effect of prescribed burning on surface runoff in a pine forest stand of Chihuahua, Mexico. Forest Ecology and Management, 137(1-3), 199-207. doi: 10.1016/S0378-1127(99)00328-X

Alfonso-Corrado, C., Campos-Contreras, J., Sánchez-García, G., Monsalvo Reyes, A., \& Clark-Tapia, R. (2014). Manejo forestal y diversidad genética de Pinus patula Schiede ex Schltdl. \& Cham, en Sierra Juárez, Oaxaca Madera. Madera y Bosques, 20(2), 11-22. doi: $10.21829 /$ myb.2014.202160

Aparicio, G. M. (2009). Efecto del manejo forestal sustentable sobre la abundancia $y$ distribución de bromelias epifitas en Capulalpam de Méndez, Oaxaca, México. Tesis de Licenciatura. Universidad Politécnica de Madrid, Madrid, España. 
Armendariz, O. R., \& Tena, V. M. (2004). Respuesta de Pinus arizonica, a diferentes densidades de aclareo. Chihuahua: Inifap-Fundación PRODUCE Chihuahua, A.C.

Balvanera, P., \& Cotler, H. (2009). Estado y tendencias de los servicios ecosistémicos. En Conabio, Capital Natural de Mexico, Vol. II: Estado de conservacion y tendencias de cambio (185-245). México: Conabio. Recuperado de: http://www.biodiversidad.gob.mx/pais/pdf/CapNatMex/VolII /II04_EdoTendenciasServiciosEcosistemicos.pdf

Bello, G. M. A., Segura, W. G., Tinoco, E. M. E., Lara, C. M. B. N., \& Salgado, G. R. (2014). Regeneración inducida de Pinus pseudostrobus Lindl., bajo diferentes densidades del dosel y preparación de sitio. Revista Mexicana de Ciencias Forestales, 6(29), 74-91. doi:10.29298/rmcf.v6i29.218

Bennett, E. M., Peterson, G. D., \& Gordon, L. J. (2009). Understanding relationships among multiple ecosystem services. Ecology Letters, 12(12), 1394-1404. doi: 10.1111/j.1461-0248.2009.01387

Buendía-Rodríguez, E., Treviño-Garza, E., Aguirre-Carderón, O. A., Alanís, R. E., \& Acosta-Mireles, M. (2015). Contenido de carbono en dos masas forestales con diferente historial de uso. En G. J. C. Wong, \& P. F. Paz (Eds.), VI Simposio Internacional del Carbono en México. Programa Mexicano de Carbono (p. 54). Villahermosa, Tabasco: Programa Mexicano de Carbón.

Castelán-Lorenzo, M., \& Arteaga-Martínez, B. (2009). Establecimiento de regeneración de Pinus patula Schl. et Cham., en cortas bajo el método árboles padres. Revista Chapingo, Serie Ciencias Forestales y del Ambiente, 15(1), 49-57.

Castellanos-Bolaños, J. F., Treviño-Garza, E. J., Aguirre-Calderón, O. A., Jiménez-Pérez, J., Musalem-Santiago, M., \& López-Aguillón, R. (2008). Estructura de bosques de pino pátula bajo manejo en Ixtlán de Juárez, Oaxaca, México. Madera y Bosques, 14(2), 51-63. doi: $10.21829 /$ myb.2008.1421212

Chacón, S. J. M. (1983). Regeneración mediante árboles padres de Pinus arizonica. Revista Ciencia Forestal, 42, 1-20.

Chacón, S. J. M., Velázquez, M. A., \& Musálem, M. A. (1998). Comportamiento de la repoblación natural de Pinus arizonica Engelm. bajo diferentes coberturas. Madera y Bosques, 4(2), 39-44. doi: 10.21829/myb.1998.421358

Corral-Rivas, J. J., Aguirre -Calderón, O. A., Jiménez-Pérez, J., CorralRivas, S. (2005). Un análisis del efecto del aprovechamiento forestal sobre la diversidad estructural en el bosque mesófilo de montaña «El Cielo», Tamaulipas, México. Investigación Agraria: Sistemas y Recursos Forestales, 14(2), 217-228.

Costanza, R., d'Arge, R., de Groot, R., Farber, S., Grasso, M., Hannon, B., Limburg, K, Naeem, S., O’Neill, R.V., Paruelo, J., Raskin, R.G., Sutton, P., \& van den Belt, M. (1997). The value of the world's ecosystem services and natural capital. Nature, 387, 253260. doi:10.1038/387253a0
Daily, G. C. (1997). Nature's services: societal dependence on natural ecosystems. Washington, D.C. : Island Press, 392 p.

Dueñez-Alanís, J., Gutiérrez, J., Pérez, L., \& Návar, J. (2006). Manejo silvícola, capacidad de infiltración, escurrimiento superficial y erosión. Terra Latinoamericana, 24(2), 233-240.

Espinoza-Martínez, L. A., Rodríguez-Trejo, D. A., \& Zamudio-Sánchez, F. J. (2008). Sinecología del sotobosque de Pinus hartwegii dos y tres años después de quemas prescritas. Agrociencia, 42(6), 717730 .

Estrada, M. O., Domínguez, P. L. A., \& Zepeda, B. M. (1995). Effects of thinnings on growth and yield in natural Pinus arizonica and Pinus durangensis stands in the El Largo-Madera region in Chihuahua State. En L. G. Eskew (Comp.). Forest health through silviculture: proceedings of the 1995 National Silviculture Workshop, Mescalero, New Mexico, May 8-11, 1995 (167-171). Fort Collins, CO: U.S. Department of Agriculture, Forest Service.

Figueroa, N. C. M. (2010). Almacenamiento de carbono en bosques manejados de Pinus patula en el Ejido La Mojonera, Zacualtipán, Hidalgo. Tesis de Maestría. Colegio de Postgraduados, Texcoco, Edo. de México, Méx.

Flores, G. J. G., Xelhuantzi, C. J., \& Chávez, D. Á. A. (2010). Fire Behavior Monitoring of a Prescribed Burn in a Pine-Oak Forest Stand. Revista Chapingo Serie Ciencias Forestales y del Ambiente, XVI(1), 49-59. doi: 10.5154/r.rchscfa.2009.05.017

Gadow, K. V., Sánchez O., S., \& Aguirre-Calderón, Ó. A. (2004). Manejo forestal con bases científicas. Madera y Bosques, 10(2), 3-16. doi: 10.21829/myb.2004.1021271

Galicia, L., \& Zarco-Arista, A. E. (2014). Multiple ecosystem services, possible trade-offs and synergies in a temperate forest ecosystem in Mexico: a review. International Journal of Biodiversity Science, Ecosystem Services y Management, 10(4), 275-288. doi:10.1080/21513732.2014.973907

Garibay-Orijel, R., Córdova, J., Cifuentes, J., Valenzuela, R., EstradaTorres, A., \& Kong, A. (2009). Integrating wild mushrooms use into a model of sustainable management for indigenous community forests. Forest Ecology and Management, 258(2), 122-131. doi: 10.1016/j.foreco.2009.03.051

Gernandt, D. S., \& Pérez-De La Rosa, J. A. (2014). Biodiversidad de Pinophyta (coníferas) en México. Revista Mexicana de Biodiversidad, 85, 126-133. doi: 10.7550/rmb.32195

Goche-Télles, R., Velázquez-Martínez, A., La Rosa, A. B. De, Terrazas, T., Cervantes-Martínez, C., \& Trinidad-Santos, A. (2003). Densidad básica y ancho de anillos de la madera de Pinus patula antes y despues de un aclareo. Interciencia, 28(12), 705-709.

Graciano-Luna, J. de J. (2001). Técnicas de evaluación dasometrica y ecológica de los bosques de coniferas bajo manejo de la Sierra Madre Occidental del Centro Sur de Durango, México. Tesis de Maestría. Universidad Autonóma de Nuevo Léon. Linares, Nuevo León, Méx. 
Haines-Young, R., \& Potschin, M. (2015). The links between biodiversity, ecosystem services and human well-being. En D. G. Raffaelli and C. L. J. Frid. (Eds.), Ecosystem Ecology: a new synthesis (Ecological Review) (110-139). Cambridge: Cambridge University Press.

Hernández-Díaz, J. C., Corral-Rivas, J. J., Quiñones-Chávez, A., BaconSobbe, J. R., \& Vargas-Larreta, B. (2008). Evaluación del manejo forestal regular e irregular en bosques de la Sierra Madre Occidental. Madera y Bosques, 14(3), 25-41. doi: 10.21829/myb.2008.1431205

Hernández-Salas, J., Aguirre-Calderón, O. A., Alanís-Rodríguez, E., Jiménez-Pérez, J., Treviño-Garza, E. J., González-Tagle, M. A., Luján-Alvarez, C., Olivas-García, J. M., Domínguez-Pereda, L. A. (2013). Efecto del manejo forestal en la diversidad y composición arbórea de un bosque templado del noroeste de México. Revista Chapingo, Serie Ciencias Forestales y del Ambiente, 19(2), 189-199. doi:10.5154/r.rchscfa.2012.08.052

Hernández-Lopez I. (2007). Cambios en la estructura y composición del bosque bajo dos tratamientos silviculturales en la Comunidad de Capulálpam de Ménder, Ixtlán, Oaxaca, México. Tesis de Maestria. Centro Agronómico Tropical de Investigación y Enseñanza (CATIE). Turrialba, Costa Rica.

Instituto Nacional de Estadística y Geografía [Inegi] (2015). Estadísticas a propósito del día internacional de los bosques (21 de Marzo). Recuperado de www.inegi.org.mx.

Instituto Nacional de Estadística y Geografía [Inegi] (2016). Anuario Estadístico de la Producción Forestal 2015. Secretaría de Medio Ambiente y Recursos Naturales (1a ed.). México: Inegi.

Jackson, R. B., Jobbágy, E. G., Avissar, R., Roy, S. B., Barrett, D. J., Cook, C. W., Farley, K. A., le Maitre, D. C., McCarl, B. A., Murray, B. C. 2005. Trading Water for Carbon with Biological Carbon Sequestration. Science, 310(5756), 1944-1947. doi: 10.1126/science.1119282

Jiménez, B. L., Damona, A., Ochoa-Gaona, S., \& Clark, T. R. (2014). Impact of silvicultural methods on vascular epiphytes (ferns, bromeliads and orchids) in a temperate forest in Oaxaca, Mexico. Forest Ecology and Management, 329, 10-20. doi: 10.1016/j.foreco.2014.05.053

Lee, H., Lautenbach, S. (2016). A quantitative review of relationships between ecosystem services. Ecological Indicators, 66, 340-351. doi: 10.1016/j.ecolind.2016.02.004

Leyva-López, J. C., Velázquez-Martínez, A., \& Ángeles-Pérez, G. (2010). Patrones de diversidad de la regeneración natural en rodales mezclados de pinos. Revista Chapingo Serie Ciencias Forestales y del Ambiente, XVI(2), 227-240. doi: 10.5154/r.rchscfa.2010.06.038

Lindeman, R. L. (1942). The trophic-dynamics aspect of ecology. Ecology, 23(4), 399-418.

Luis-Mejía, S., Gómez-Guerrero, A., Etchevers-Barra, J. D., ÁngelesPérez, G., López-López, M. A., \& Horwath, W. R. (2007).
Acumulación de carbono orgánico en el suelo en reforestaciones de Pinus michoacana. Agrociencia, 41(7), 711-721.

Luna-Bautista, L. (2014). Aprovechamiento forestal y su impacto en la vegetación y propiedades físicas del suelo en Santa Catarina Ixtepeji, Oaxaca. Tesis de Maestría, Colegio de Postgraduados. Texcoco, Edo. de México, Méx.

Luna-Bautista, L., Hernández-De La Rosa, P., Velázquez-Martínez, A., Gómez-Guerrero, A., Acosta-Mireles, M. (2015). El sotobosque en la composición y diversidad de áreas bajo manejo forestal en Santa Catarina Ixtepeji, Oaxaca. Revista Chapingo Serie Ciencias Forestales y del Ambiente, 21(1), 109-121. doi: 10.5154/r.rchscfa.2014.08.037

Mace, G. M., Norris, K., Fitter, A. H. (2012). Biodiversity and ecosystem services: A multilayered relationship. Trends in Ecology and Evolution, 27(1), 19-25. doi:10.1016/j.tree.2011.08.006

Masera, O. R., Ordóñez, M. J., Dirzo, R. (1997). Carbon emissions from Mexican forests: Current situation and long-term scenarios. Climatic Change, 35(3), 265-295. doi:10.1023/A:100530

Millennium Ecosystem Assessment [MEA] (2005). Ecosystems and human well-being: Synthesis. Ecosystems (Vol. 5). Washington, DC: Island Press.

Mintzer I. M. 1992. Confronting climate change. Risk implications and responses. Cambridge: University Press.

Muñoz-Villers, L. E., Holwerda, F., Gómez-Cárdenas, M., Equihua, M., Asbjornsen, H., Bruijnzeel, L. A., \& Tobón, C. (2012). Water balances of old-growth and regenerating montane cloud forests in central Veracruz, Mexico. Journal of Hydrology, 462-463, 53-66. doi: 10.1016/j.jhydrol.2011.01.062

Návar-Chaídez, J. de J., \& González-Elizondo, S. (2009). Diversidad, estructura y productividad de bosques templados de Durango, México. Polibotánica, 27, 71-87.

Negreros, C. P., \& Snook, L. K. (1984). Análisis del efecto de la intensidad de corta sobre la regeneración natural de pinos en un bosque de pino-encino. Ciencia Forestal, 9(47), 48-61.

Núñez-López, D. (2015). Dinámica de la producción de biomasa por efecto de las intervenciones silvícolas aplicadas en bosques regulares del Ejido El Largo y Anexos en Chihuahua. En G. J. C. Wong, \& P. F. Paz (Eds.), VI Simposio Internacional del Carbono en México. Programa Mexicano de Carbono. (p. 81). Tabasco, México: Programa Mexicano de Carbono.

Ordóñez-Díaz, J. A. B., Rivera Vázquez, R., Tapia Medina, M. E., \& Ahedo Hernández, L. R. (2015). Contenido y captura potencial de carbono en la biomasa forestal de San Pedro Jacuaro, Michoacán. Revista Mexicana de Ciencias Forestales, 6(32), 7-16. doi:10.29298/rmcf.v6i32.95

Pacheco-Aquino, G., Durán-Medina, E., \& Ordóñez-Díaz, J. A. (2014). Estimación del carbono arbóreo en el área de manejo forestal de 
Ixtlán de Juárez, Oaxaca, México. Revista Mexicana de Ciencias Forestales, 6(29), 126-145. doi:10.29298/rmcf.v6i29.221

Pavón, N. P., Moreno, C. E., \& Ramírez-Bautista, A. (2012). Biomasa de raíces en un bosque templado con y sin manejo forestal en Hidalgo, México. Revista Chapingo Serie Ciencias Forestales y del Ambiente, XVIII(3), 303-312. doi:10.5154/r.rchscfa.2011.07.052

Pérez-Ramírez, S., Ramírez, M. I., Jaramillo-López, P. F., \& Bautista, F. (2013). Contenido de carbono orgánico en el suelo bajo diferentes condiciones forestales: reserva de la biosfera mariposa monarca, México. Revista Chapingo, Serie Ciencias Forestales y del Ambiente, 19(1), 157-173. doi:10.5154/r.rchscfa.2011.09.062

Pérez-Segura, B. L., Guerra de la Cruz, V., Carrillo Anzures, F., Acosta Mireles, M., \& Buendía Rodríguez, E. (2007). Respuesta de la regeneración natural en dos sistemas silvícolas aplicados en Tlaxco, Tlaxcala. Revista Mexicana de Ciencias Forestales, 32(102), 39_ 56.

Ramírez-Santiago, R. (2006). Efectos de la aplicación de dos métodos de regeneración sobre la estructura, diversidad y composición de un bosque de pino-encino en la Sierra de Juárez de Oaxaca, México. Tesis de Maestría, Centro de Agronómico Tropical de Investigaciones y Enseñanza (CATIE). Turrialba, Costa Rica.

Ramírez-Santiago, R., Ángeles Pérez, G., Clark Tapia, R., Cetina Alcalá, V. M., Plascencia Escalante, O., \& Hernández de la Rosa, P. (2015). Efectos del manejo forestal en la repoblación de Pinus spp. en la Sierra Norte de Oaxaca, México. Revista Mexicana de Ciencias Forestales, 6(32), 49-62. doi:10.29298/rmcf.v6i32.98

Razo-Zárate, R., Gordillo-Martínez, A. J., Rodríguez-Laguna, R., Maycotte-Morales, C. C., \& Acevedo-Sandoval, O. A. (2013). Escenarios de carbono para el bosque de oyamel del Parque Nacional El Chico, Hidalgo, México. Revista Latinoamericana de Recursos Naturales, 9(1), 17-21.

Rodriguez, G. (2010). Efecto de aclareos en el crecimiento de una plantación de Pinus patula Schl. et Cham. en Ixtlán, Oaxaca. Tesis de Doctorado, Colegio de Postgraduados. Texcoco, Estado de México, Méx.

Rodríguez, J. P., Beard, T. D., Bennett, E. M., Cumming, G. S., Cork, S. J., Agard, J., .. Peterson, G. D. (2006). Trade-offs across Space, Time, and Ecosystem Services. Ecology and Society, 11(1), 28.

Rzedowski, J. (1991). Diversidad y origenes de la flora fanerogámica de México. Acta Botanica Mexicana, 14, 3-21. doi:10.21829/abm14.1991.611 .

Sánchez H., M. (2016). Crecimiento e incremento de un rodal de Pinus rudis Endl. como respuesta a diferentes intensidades de aclareo en San José de la Joya, Galeana, Nuevo León. Tesis de Licenciatura, Universidad Autónoma Agraria Antonio Narro. Saltillo, Coahuila, Méx.

Saynes, V., Etchevers, J. D., Galicia, L., Hidalgo, C., \& Campo, J. (2012). Soil carbon dynamics in high-elevation temperate forests of Oaxaca (Mexico), Thinning and rainfall effects. Bosque, 33(1), 311. doi:10.4067/S0717-92002012000100001
Sing, L., Ray, D., \& Watts, K. (2015). Ecosystem services and forest management. Research Note - Forestry Commission. Edinburgh: Forestry Commission, $10 \mathrm{p}$.

Solís, H. A., Nájera, L. J. A., Méndez, G. J., Vargas, L. B., Álvarez, G. M. (2014). Carbono orgánico del suelo en rodales silvícolas del ejido La Victoria, Pueblo Nuevo, Durango. Investigación y Ciencia, 22(63), $5-11$.

Solís, M. R., Aguirre, C. O., Treviño, G. E., Jiménez, P. J., Jurado Y., E., \& Corral, R. J. (2006). Efecto de dos tratamientos silvícolas en la estructura de ecosistemas forestales en Durango, México. Madera y Bosques, 12(2), 49-64. doi: 10.21829/myb.2006.1221242

Soriano-Luna, M., Martínez-Trinidad, T., Plasencia-Escalante, \& O., Razo-Zárate, R. (2014). Estimacion de biomasa y carbono en bosque manejados de Zacualtipan, Hidalgo. Tesis. Colegio de Postgraduados. Texcoco, Edo. de México, Méx.

Tansley, A. G. (1935). The Use and Abuse of Vegetational Concepts and Terms. Ecology, 16(3), 284-307. doi: 10.2307/1930070

Tipper R. 1998. Update on carbon offsets. Tropical Forest Update. 8(1), 2 5.

Torres-Rojo, J. M., \& Guevara, S. A. (2002). El potencial de México para la producción de servicios ambientales: captura de carbono y desempeño hidráulico. Gaceta Ecológica, (63), 40-59.

Torres-Rojo, J. M., Moreno-Sánchez, R., \& Mendoza-Briseño, M. A. (2016). Sustainable Forest Management in Mexico. Current Forestry Reports, 2(2), 93-105. doi:10.1007/s40725-016-0033-0

Torres-Rojo, J. M. (2004). Estudio de tendencias y perspectivas del Sector Forestal en América Latina. Documento de Trabajo. Informe Nacional México.

Valdés, M., Asbjornsen, H., Gómez-Cárdenas, M., Juárez, M., \& Vogt, K. A. (2006). Drought effects on fine-root and ectomycorrhizalroot biomass in managed Pinus oaxacana Mirov stands in Oaxaca, Mexico. Mycorrbiza, 16(2), 117-124. doi:10.1007/s00572-0050022-9.

Valdés, M., Córdova, J., Gómez, M., \& Fierros, M. A. (2003). Understory vegetation and ectomycorrhizal sporocarp diversity response to pine regeneration methods in Oaxaca, Mexico. Western Journal of Applied Forestry, 18(2), 101-108. doi:10.1093/wjaf/18.2.101

Valdés, M., Cordova, J., Valenzuela, R., \& Fierros, A. M. (2004). Incremento del fitopatógeno Armillaria mellea (Vahl.:Fr.) Karsten en bosque de pino-encino, en relación al grado de disturbio por tratamiento silvícola. Revista Chapingo. Serie Ciencias Forestales y Del Ambiente, 10(2), 99-103.

Valdés, M., Pereda, V., Ramírez, P., Valenzuela, R., \& Pineda, R. M. (2009). The ectomycorrhizal community in a Pinus oaxacana forest under different silvicultural treatments. Journal of Tropical Forest Science, 21(2), 88-97.

Valencia, A. S. (2004). Diversidad del género Quercus (Fagaceae) en México. Boletin de La Sociedad Botánica de México, 75, 33-53. 
Monárrez-González et al. Efecto del manejo forestal sobre algunos servicios ecosistémicos

Valencia, V. J. (1992). Análisis de la regeneración después del tratamiento de" árboles padre" en Atenquique, Jalisco. Revista Mexicana de Ciencias Forestales, 17(21), 63-85.

Vázquez, B. E. (2015). Efecto de aclareos en una regeneración natural de Pinus rudis Endl. en San José de la Joya, Galeana, Nuevo León. Tesis de Licenciatura, Universidad Autónoma Agraria Antonio Narro. Saltillo, Coahuila, Méx.

Vera-Vilchis, V., \& Rodríguez-Trejo, D. A. (2007). Supervivencia e incremento en altura de Pinus hartwegii a dos años de quemas prescritas e incendios experimentales. Agrociencia, 41(2), 219-230.

Villanueva-Jiménez, E., Villegas-Ríos, M., Cifuentes-Blanco, J., \& LeónAvendaño, H. (2006). Diversidad del género Amanita en dos áreas con diferente condición silvícola en Ixtlán de Juárez, Oaxaca, México. Revista Mexicana de Biodiversidad, 77, 17-22.

Wolf, J. H. D. (2005). The response of epiphytes to anthropogenic disturbance of pine-oak forests in the highlands of Chiapas,
Mexico. Forest Ecology and Management, 212(1-3), 376-393. doi:10.1016/j.foreco.2005.03.027

Manuscrito recibido el: 19 de mayo de 2017

Aceptado el: 30 de enero de 2018

Publicado el: 22 de agosto de 2018

Este documento se debe citar como:

Monárrez-González, J. C., Pérez-Verdín, G., López-González, C., Márquez-Linares, M. A. y González-Elizondo, M. S. (2018). Efecto del manejo forestal sobre algunos servicios ecosistémicos en los bosques templados de México. Madera y Bosques, 24(2), e2421569. doi: $10.21829 / \mathrm{myb} .2018 .2421569$

Madera y Bosques por Instituto de Ecología, A.C. se distribuye bajo una Licencia Creative Commons Compartirlgual 4.0 Internacional. 